\title{
Ocular tension and axial length of the eyeball in open-angle glaucoma and low tension glaucoma
}

\author{
D. A. LEIGHTON AND A. TOMLINSON \\ Manchester Royal Eye Hospital
}

Ocular tension is influenced by eyeball size in normal eyes. Abdalla and Hamdi (1970) found a higher ocular tension in subjects with myopic eyes than in those with emmetropic eyes in most age groups, and Tomlinson and Phillips (1970) found a higher ocular tension in normal subjects with high axial length of eyeball and myopia than in those with small axial length and hypermetropia. These findings were supported by the results of a study of ocular tension in anisometropic children (Tomlinson and Phillips, 1972) though these results are not supported by Bengtsson (1972). The high cup-to-disc ratio with which a high axial length of eyeball is associated (Tomlinson and Phillips, 1969) as well as high ocular tension (Tomlinson and Phillips, 1970) may explain the unduly high prevalence of myopic eyes in both open-angle glaucoma (Weekers, Lavergne, and Prijot, 1958; Perkins and Jay, 1960) and low tension glaucoma (Perkins, I959).

Nevertheless, large size of eyeball is not a particularly characteristic feature of eyes with open-angle glaucoma when compared with normal eyes if those with low tension glaucoma are disregarded (Tomlinson and Leighton, 1972), although variation in size of eyeball may still have an important modifying effect.

\section{Method}

In order to see if eyeball size is an important variable in open-angle glaucoma, axial length of eyeball was measured and the maximum applanation tension which had been recorded was noted in seventeen patients with open-angle glaucoma and thirteen patients with low tension glaucoma.

All the patients had been diagnosed as having glaucoma (but see below for criteria) between 5 and $2 \frac{1}{2}$ years before the time of inclusion in the survey and all had therefore at that time been attending the Glaucoma Clinic for at least $2 \frac{1}{2}$ years. The age and refraction of the patients are shown in the Table.

The seventeen patients with open-angle glaucoma comprised seven males and ten females and all had:

(a) Pathological cupping of the optic discs;

(b) Visual field defects on the Bjerrum screen of a type found in glaucoma;

(c) A maximum recorded applanation tension of more than $23 \mathrm{~mm} . \mathrm{Hg}$;

(d) Filtration angles open at a time of raised ocular tension and not considered liable to closure.

The thirteen patients with "low tension" glaucoma comprised six males and seven females. The only difference from the above criteria for open-angle glaucoma was that $(c)$, the maximum recorded applanation tension, was not greater than $23 \mathrm{~mm}$. $\mathrm{Hg}$.

Received for publication January 8, 1973 
In-patient phasing for at least one morning had been done in twelve of the thirteen patients with "low tension" glaucoma, and twelve of the seventeen patients with open-angle glaucoma. In some patients all the above diagnostic criteria were not fulfilled for one eye and so the other eye was used for analysis. Otherwise the eye to be included was chosen at random.

Axial length of eyeball was measured in each patient by the addition of:

(a) Depth of the anterior chamber (including corneal thickness) found by the Type II depthmeasuring attachment for the Haag-Streit 9oo slit lamp;

(b) Thickness of the crystalline lens

(c) Length of the vitreous body

from an antero-posterior axis trace of the \} eye obtained by A-scan ultrasonography

Treatment with pilocarpine drops was stopped for 48 hours and treatment with tosmilen bromide drops was stopped for 2 weeks before measurement of the above dimensions. Wilkie, Drance, and Schulzer (1969) noted a reduction in anterior chamber depth in patients taking miotic eye drops.

\section{Results}

The Figure shows a correlation between maximum recorded applanation tension and axial length of eyeball in the seventeen patients with open-angle glaucoma. Patients with small eyeballs tended to have a high maximum ocular tension and those with large eyeballs

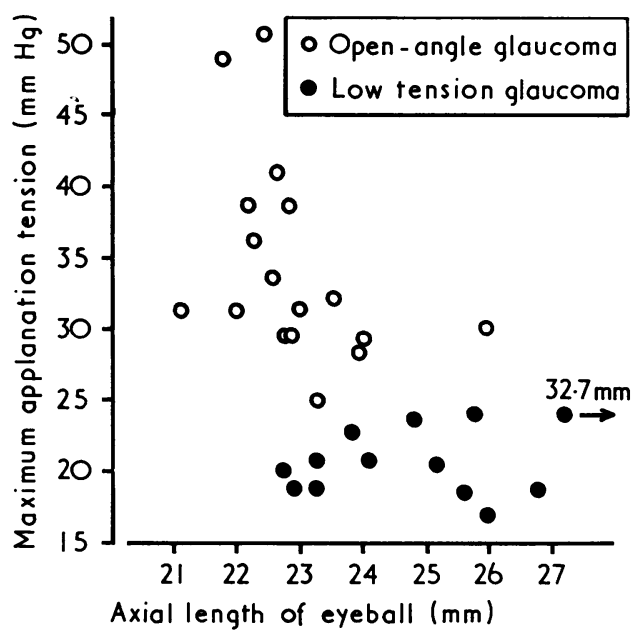

FIGURE Axial length of eyeball and maximum recorded ocular tension in seventeen patients with open-angle glaucoma and thirteen patients with low tension glaucoma

A significant correlation was found for open-angle glaucoma $\left(r_{\mathrm{s}}=-0.618 ; \mathrm{P}<0.01\right)$ but not for low tension glaucoma $\left(r_{s}=+0 \cdot 104 ; P>0 \cdot 05\right)$. When both groups were considered together, a significant correlation was found $\left(r_{\mathrm{s}}=-0 \cdot 44^{2} ; \mathrm{P}<0 \cdot 0 \mathrm{r}\right)$

a lower maximum ocular tension ( $\left.\mathrm{n}=\mathrm{I} 7 ; r_{\mathrm{s}}=-0.6 \mathrm{I} 8 ; \mathrm{P}<0 \cdot 0 \mathrm{I}\right)$.

No correlation between axial length and maximum recorded applanation tension was found, however, in the thirteen patients with low tension glaucoma $\left(r_{\mathrm{s}}=+0.104\right.$; $\mathrm{P}>0 \cdot 05)$.

For the low tension and open-angle glaucoma groups combined, a significant association between small axial length and high maximum applanation tension was found $(\mathrm{n}=30$; $\left.r_{\mathrm{s}}=-0 \cdot 442 ; \mathrm{P}<0 \cdot 0 \mathrm{I}\right)$.

No significant differences were found between the ages of the patients in the two groups (Table).

Low tension glaucoma eyes were significantly more myopic than open-angle glaucoma eyes $\left(\mathrm{U}^{*}=58 ; 0 \cdot 0 \mathrm{I}<\mathrm{P}<0 \cdot 05\right)$, and had significantly greater axial lengths $\left(\mathrm{U}^{*}=3^{2}\right.$; $\mathrm{P}<0 \cdot 005)$.

* A Mann-Whitney U test was used (Siegel, 1956). 
Table Particulars of thirty patients

\begin{tabular}{|c|c|c|c|}
\hline Diagnosis & $\begin{array}{l}\text { Open angle } \\
\text { glaucoma }\end{array}$ & $\begin{array}{l}\text { Comparison } \\
U(0 \cdot 05)=70\end{array}$ & $\begin{array}{l}\text { Low tension } \\
\text { glaucoma }\end{array}$ \\
\hline No. of Patients & 17 & 30 & 13 \\
\hline $\begin{array}{l}\text { Mean age (yrs) } \\
\text { at maximum } \\
\text { applanation tension }\end{array}$ & 71 & $\begin{array}{l}\mathrm{U}=77.5 \\
\mathrm{P}>0.05\end{array}$ & 63 \\
\hline $\begin{array}{l}\text { Mean refraction } \\
\text { (Diopters - best } \\
\text { sphere) }\end{array}$ & $0 \cdot 00$ & $\begin{array}{l}\mathrm{U}=5^{8 *} \\
0.01<\mathrm{P}<0.05\end{array}$ & $-5 \cdot 10$ \\
\hline $\begin{array}{l}\text { Mean axial length } \\
\text { of eyeball }\end{array}$ & $22 \cdot 90$ & $\begin{array}{l}\mathrm{U}=32^{*} \\
\mathrm{P}<0.005\end{array}$ & $25 \cdot 16$ \\
\hline $\begin{array}{l}\text { Mean maximum } \\
\text { applanation tension }\end{array}$ & $34 \cdot 3$ & $\begin{array}{l}\mathrm{U}=0^{*} \\
\mathrm{P}<0 \cdot 00 \mathrm{I}\end{array}$ & $19 \cdot 8$ \\
\hline
\end{tabular}

The Mann-Whitney U Test (Siegel, 1956) was used to compare the data from the two groups.

For each comparison $\mathrm{U}$ for $\mathrm{P}=0.05$ is indicated.

*Significant difference found.

\section{Discussion?}

The tendency in patients with open-angle glaucoma for small size of eyeball to be associated with a high ocular tension and large size of eyeball with a lower maximum ocular tension shows the marked modifying effect of eyeball size and its associations, especially the cupto-disc ratio, on the pattern of open-angle glaucoma. The extreme is found in the case of low tension glaucoma which in the largest size of eyeball was found in this series.

A continuous variation is thus present between the smallest eyeballs with a very high ocular tension, and the largest eyeballs with the lowest though still "raised" ocular tension which is usually found in "low tension" glaucoma (see Tomlinson and Leighton, 1972). Hence, in order for open-angle glaucoma to occur in a small eyeball, the ocular tension must be especially high to offset the effect of a relative non-susceptibility of the optic disc to raised ocular tension. Conversely, in large eyeballs, the large cup-to-disc ratio is relatively highly susceptible to raised ocular tension (Armaly and Sayegh, I969) and an ocular tension which is only slightly raised is sufficient to result in pathological cupping of the optic disc.

Our results therefore suggest that open-angle glaucoma arises from a fairly fixed relationship between axial length of eyeball and applanation tension; a critical level of ocular tension has been reached and is apparently not exceeded to any marked degree. This fixed relationship does not apply in cases of low tension glaucoma although this might have been expected, as such eyes are usually large (Tomlinson and Leighton, 1972). The explanation for this lack of correlation between axial length of eyeball and maximum recorded applanation tension may be that some low tension glaucoma eyes have previously passed through a phase of ocular hypertension, during which loss of visual field has resulted. Nevertheless, patients reported here with low tension glaucoma generally continued to lose field in just the same way as those with open-angle glaucoma. A small residual area of visual field was, however, associated with small axial length of eyeball ( $\mathrm{n}=30-$ open angle and low tension glaucoma patients combined; $r_{\mathrm{s}}=+0.468 ; \mathrm{P}<0.0 \mathrm{I}$ ), though this may have been due to age, i.e. the associations of old (great) age and a small residual 
area of visual field $\left(\mathrm{n}=30 ; r_{\mathrm{s}}=-0.398 ; 0 \cdot 0 \mathrm{I}<\mathrm{P}<0.05\right)$ and old (great) age and a small axial length $\left(\mathrm{n}=30 ; r_{\mathrm{s}}=-0.570 ; \mathrm{P}<0.0 \mathrm{I}\right)$ in our series. (This last correlation agrees with the observations of Perkins and Jay ( 1960 ) on the high incidence of myopia in young patients with open-angle glaucoma.)

The inverse relationship which we have found in open-angle glaucoma between maximum recorded applanation tension and axial length of eyeball is the reverse of that found in normal eyes, in which Tomlinson and Phillips (1970) found an association between high axial length of eyeball and a slightly high, though still normal, applanation tension. No contradiction arises because our thirty patients had definite glaucoma, i.e. seventeen patients had open-angle glaucoma and thirteen had low tension glaucoma (each of them with a field defect). Presumably a threshold relationship between axial length of eyeball and applanation tension had been reached which had resulted in visual field defects; that is, for a given size of eyeball, a critical level of intraocular pressure must be reached before glaucomatous cupping and the associated visual field defects occur, such that only a slight elevation of intraocular pressure is required in large eyeballs and a greater elevation is necessary in smaller eyeballs. The effect of eyeball size in open-angle glaucoma is probably one important facet in the multifactorial nature of the disease.

\section{Summary}

In seventeen patients with open-angle glaucoma, a small axial length of eyeball was associated with a high maximum ocular tension $(\mathrm{P}<0.0 \mathrm{r})$. No such correlation was found in thirteen patients with low tension glaucoma, although when the open-angle and low tension glaucoma groups were combined, the inverse correlation between axial length and maximum ocular tension was present $(P<0.01)$.

The marked modifying effect of eyeball size in open-angle glaucoma is evident; in order for pathological cupping and glaucomatous visual field defects to occur in large eyeballs, the ocular tension needs to be only slightly raised. Conversely, in small eyeballs, the critical level of ocular tension for the development of field defects needs to be higher to offset the lower susceptibility of the optic disc.

Low tension glaucoma patients were significantly more myopic $(0 \cdot 0 \mathrm{I}<\mathrm{P}<0 \cdot 05)$ and had significantly greater axial lengths $(\mathrm{P}<0 \cdot 005)$ than open-angle glaucoma patients.

\section{References}

ABDAlla, м. I., and hamdi, м. (1970) Brit. F. Ophthal., 54, 122

ARMALY, M. F., and SAYEgh, R. E. (1969) Arch. Ophthal. (Chicago), 82, I9 I

BENGTSSON, B. (1972) Acta ophthal. (Kbh.), 50, 445

Perkins, E. s. (1959) Proc. roy. Soc. Med., 52, 429

and JAY, B. s. (1960) Trans. ophthal. Soc. U.K., 80, I 53

siegel, s. (1956) "Non Parametric Statistics for the Behavioural Sciences", p. I i6. McGraw-Hill, New York

TOMLinson, A., and Leighton, D. A. (1972) Brit. 7. Ophthal., 56, 97 and PHILlips, c. I. (I969) Ibid., 53, 765

$\longrightarrow$ (1970) Ibid., 54, $54^{8}$

- (1972) Acta ophthal. (Kbh.), 50, 872

Weekers, R., LAVergne, G. and Prijot, e. (1958) Ann. Oculist. (Paris), rgr, 26

Wilkie, J., Drance, s. M., and schulzer, m. (1969) Amer. J. Ophthal., 68, 78 